\title{
Towards an Account of Intuitiveness
}

\author{
Phil Turner \\ School of Computing, Napier University \\ Edinburgh, EH10 5DT \\ p.turner@napier.ac.uk
}

\begin{abstract}
Intuitive systems are usable systems. Design guidelines advocate intuitiveness and vendors claim it but what does it mean for a user interface, interactive system or device to be intuitive? A review of the use of the term "intuitive" indicates that it has two distinct but overlapping meanings, namely intuitiveness based on familiarity and intuitiveness reflecting our embodiment (and frequently both). While everyday usage indicates that familiarity means either a passing acquaintance or an intimacy with something or someone, it will be concluded that familiarity might best be equated with "knowhow" which in turn is based on a deep, often tacit, understanding. The intuitive nature of tangible user interfaces will in turn be attributed to embodiment rather than tangibility per se. Merleau-Ponty writes that it is through our bodies that we "prehend" the world. A number of disciplines now regard actionperception as so closely coupled that they are better considered as a dyad rather than separately. A modified treatment of action-perception coupling is proposed, with familiarity providing an epistemic core, as the basis of intuitiveness.
\end{abstract}

Keywords: intuitiveness, familiarity, embodiment, action-perception coupling, affordance.

\section{Introduction}

This paper examines one of the most fundamental, most desirable of attributes of human-computer interaction (HCI) namely it should be intuitive. For many years design guidelines have recommended that systems should be created so that their use is intuitive. This has been interpreted as ease to use, or ease of learning, being consistent or being familiar, in taking advantage of existing skills and knowledge; or employ something familiar from the real world by way of a metaphor (e.g. Bewley et al., 1983; Shneiderman, 1992; Hartson and Hix, 1993; Raskin, 1994) among very many others). For almost as many years designers and vendors have promoted their systems and devices as being intuitive. Yet for a concept which lies at the heart of interaction design, HCI is remarkably vague on agreeing what is meant by intuitiveness, how it works and just how many aspects of interaction intuitiveness represents. For example, when we describe the use of the desktop metaphor and the use of a joystick as being intuitive are we describing the same attribute?

In everyday usage, intuitive means automatic or without requiring conscious thought, there is also a suggestion of the visceral ("gut feeling"). Intuitiveness, by definition arises from our intuitive faculties, or intuition, which women are said to have in abundance, again implying (pejoratively) the affective rather than rational. Perhaps the most frequently cited aspect of intuition is an individual's sense of what is right or wrong and of making an appropriate or inappropriate response in a given context while largely remaining ignorant of the reasons for that mental state (Westcott, 1968). Finally, in the Dreyfus and Dreyfus model of skill acquisition (1988) intuitiveness is attributed to their highest level of achievement, namely, that of expert. An expert is someone who, paradoxically, no longer relies on rules or guidelines and has an intuitive grasp of situations based on deep tacit understanding.

\subsection{The Marketing of Games Consoles}

It is worth taking a moment to consider the origin of the current discussion which was prompted by a number of reviews of the new generation of games consoles which are currently being promoted by their respective manufacturers.

At the time of writing, three major vendors are actively promoting their new games consoles. Microsoft was first on the market with Xbox 360 with its impressive graphics and sound capabilities; Sony's PS3 also boasts impressive graphics and sound; while Nintendo's Wii (with its impressive graphics and sound) has a pair of controllers (input devices) described as the "Wii-mote control" and 
the "nunchuck" (which will not be discussed further). Images of the Wii-mote control can be seen below in figure 1 .

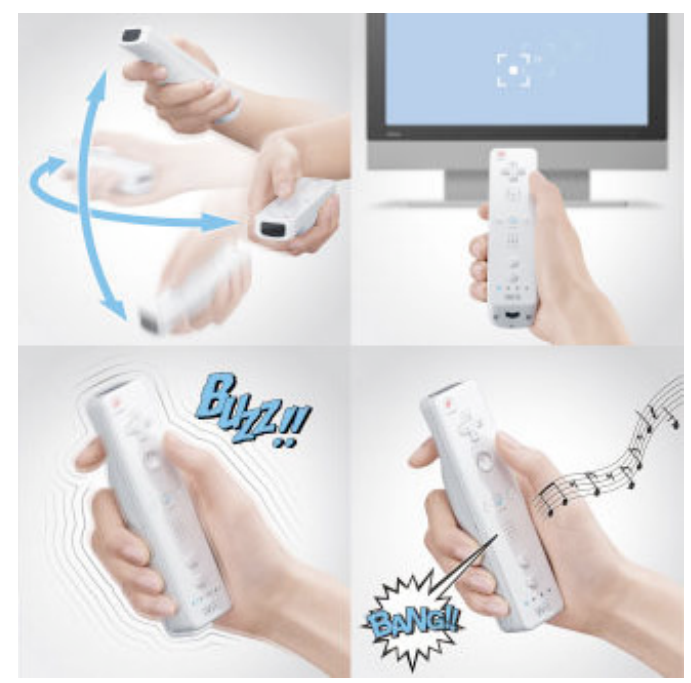

Figure 1: the Nintendo Wii-mote control (www.nintendo.com)

Reviewers have noted that this device is particularly intuitive. As can be seen from the figure, it looks like a TV remote control (hence, I assume, its name) which wirelessly communicates with the games console. It also has internal and external sensors which detect its movement and orientation so that in addition to using it as a pointing device it can also be used as a 'baseball bat', a 'sword' or a 'tennis racket'. Figure 2 illustrates a game of baseball being played on the Nintendo Wii with the player using the Wii-mote control as though it was a baseball bat.

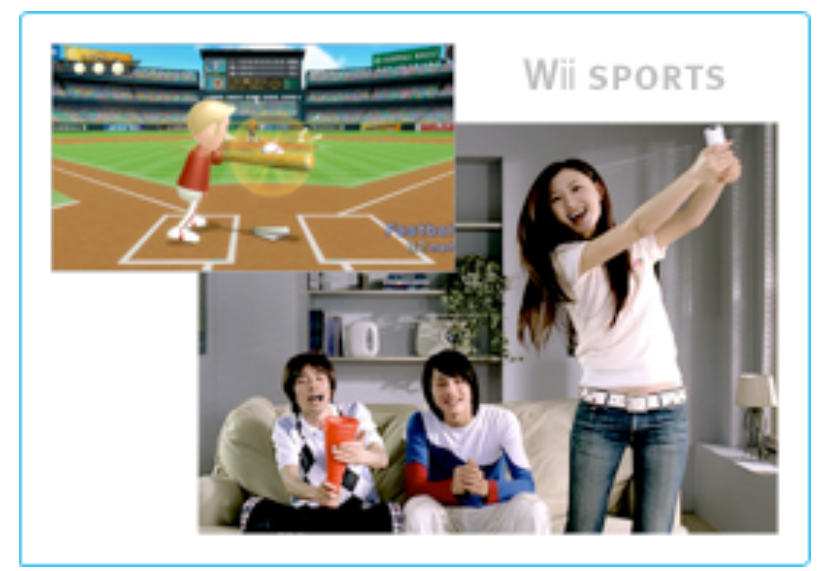

Figure 2: the Nintendo Wii-mote control in action (www.nintendo.com)

Thus the Wii-mote control offers a style of interaction which is both familiar and tangible. It looks and behaves like a familiar TV remote control while also offering a tangible style of interaction.

\subsection{The structure of this paper}

The argument presented here is an attempt to "deconstruct" the concept of intuitiveness. The term intuitive is used in many different ways in HCI but there are two distinct groupings which correspond to intuitiveness as familiarity and intuitiveness as embodiment. Familiarity and embodiment are then considered from successive HCI, philosophical and psychological perspectives. In these discussions to recurrent themes emerge namely, perception and affordance. It is concluded that intuitiveness can be described in terms of a modified account of action-perception coupling. 


\section{Two Views of Intuitiveness}

\subsection{Intuitiveness and Familiarity}

From an HCI perspective, Raskin (1994) has famously argued that to be intuitive means to be familiar. $\mathrm{He}$ writes that a user interface is intuitive in as it much as it resembles (or is identical) to something the user already knows. He continues, "In short, intuitive in this context is an almost exact synonym of familiar". Later, and at greater length, he writes "one of the most laudatory terms used to describe an interface is to say that it is intuitive. When examined closely, this concept turns out to vanish like a pea in a shell game and be replaced with the more ordinary but more accurate term familiar" (Raskin, 2000). Similarly Kara et al. (1997) have also posed the question "Are what we call "intuitive" user interfaces really just familiar user interfaces?" There numerous design guidelines which echo this directing the HCI specialist to make use of the familiar and to date this has been achieved by way of the wide spread use of metaphor, the most familiar of which is the desktop metaphor.

In our everyday lives we acquire knowledge of a real world desktops and have found that they support a large number of activities such as placing things on them, sitting at them, working at them and so forth - in other words we have directly perceived their affordances. But this is essentially a reciprocal relationship whereby our perception of objects' affordances makes us familiar with them and our very familiarity allows us to perceive their affordances. Such knowledge is by definition intuitive, however to make use of it when using an interactive device requires us to make inferences from these intuitions ${ }^{1}$. Thomson, in discussing the relative merits and status of intuitive and inferential knowledge, observes:

"Intuition and Inference usually are contrasted with each other as being two separate and
antithetical modes of mental experience. Intuition is generally referred to as primary and
fundamental, while Inference is accounted secondary and superstructive. But as far as one has
been made dependent upon the other, mankind has been disposed to measure Inference by
Intuition rather than Intuition by Inference. Intuition has been regarded as a source of or
method of obtaining transcendental, pure and trustworthy knowledge; while Inference has
been esteemed to yield only experiential, mixed and uncertain information." 1878: 339 (capitalisation in the original) Thus the creators of the desktop metaphor assumed that people could make inferences about the behaviour of the computer-based desktop from their (intuitive) knowledge of real desktops. Metaphor is more pervasive in HCI than may be at first sight is apparent - consider the ubiquity of "cut and paste" and reference to web "pages". The Xerox Star was not only the first system to employ the desktop metaphor but the first to use toolbox metaphor (e.g. Johnson et al., 1989) but elsewhere more exotic metaphors such as magic wands (e.g. Bowman et al., 2001); breadcrumbs (e.g. Darken and Silbert, 1993); muddy footprints (e.g. Marcus, 1993) among dozens of other have been employed to communicate the designers' intent to the systems' users.

A great deal has been written about the role of metaphor in HCI and space does not permit an extended discussion of this, safe to say that its advocates claim that it reflects the very basis of our cognition (e.g. Lakoff and Johnson, 1999; Fauconnier and Turner, 2003) while others advise caution and regard it potentially harmful (Halasz and Moran, 1982). However Holyoak and Thagard (1995) have convincing argued for the mechanism by which metaphor and analogy operate. They describe metaphor as involving saying one thing in order to say another. A metaphor thus connects two different domains just as an analogy works by mapping a 'source' and a 'target'. Thus metaphor and analogy can connect, in the minds of the users, real world objects with corresponding elements and attributes of interactive devices hence the power of familiar source domains.

\footnotetext{
${ }^{1}$ Norman (1988), who introduced the concept of affordance to HCI, sought to adapt the original, direct unlearned formulation with one which is at one remove, namely perceived affordance. He suggested that an individual could be said to perceive the intended behaviour of, say, interface widgets such as the sliders and buttons. The intended and perceived behaviours of such widgets are, of course, very simple, including sliding, pressing and rotating leaving him to conclude that 'real affordances are not nearly as important as perceived affordances; it is perceived affordances that tell the user what actions can be performed on an object and, to some extent, how to do them' (ibid). Like Gibson, however, he subsequently modified his position on user interface affordances to observe that they are 'often more about conventions than about reality' (Norman, 1999:124).
} 


\subsection{Familiarity}

Familiarity means a thorough knowledge of, or an intimacy with something or someone. Etymologically it is related to family. Familiarity is commonplace and everyday and aside from familiarity as intimacy, it can also be used to indicate a passing acquaintance. For example, my train to work has an automated announcement asking passengers to familiarise themselves with the safety procedures. Yet familiarity, in either sense, has not received sustained attention in the field of human computer interaction excepting perhaps some of our recent work (Van De Walle et al., 2003; Turner et al., 2004). In an attempted to define it more clearly we have turned to the work of Martin Heidegger who discussed it at some length ${ }^{2}$. Heidegger is best known for his hyphenated treatment of our beingin-the-world, which for him, captures the fundamental questions of ontology. For Heidegger, to exist is to be in the world (better thought of a social world rather than planet Earth as such) and his use of hyphens indicates that we are not and cannot be separated from this fact. Heidegger has argued that familiarity is a consequence of being-in-the-world and is the basis of our worldliness, that is, our ability to deal with the world. In short, we are able to cope with the world and the systems it comprises because we are familiarity with it.

Familiarity encompasses the ideas of involvement and understanding. Involvement may be thought of as an expansion of the word in as found in 'being-in-the-world' while understanding should be interpreted as 'know-how'. Dreyfus (1991) notes that "This know-how ... is more basic than the distinction between thought and action" and directly equates humans with these skills ("We are such skills"). In these terms, being familiar with a computer should be understood in terms of being able use it or better still being able to cope with it. Coping, in turn, may be understood in terms of three key characteristics, firstly, it is the recognition that equipment is inter-related. Each piece of equipment being used for a specific task - hammers are for driving nails into wood; a word processor is used to compose text. The second 'component' of the world is the set of purposes to which these tasks are put. Of course, while we cannot meaningfully separate out purposes from tasks in these worlds we can recognize that the word processor is used to write an academic paper for the purpose of publication and dissemination. Nails are driven into wood to provide illustrations for philosophical discourse. Finally, in performing these tasks we acquire or assume an identity (or identities) as carpenters, academics and so forth. In adopting these concepts and perspectives we are move away from reflecting on the nature of things to how we use, manage and cope with them. Thus we demonstrate our familiarity with the world by coping with situations, tools and objects. Familiarity is then a 'readiness' to cope with, say, chairs (e.g. by sitting on them and by being able to sit in them) which has developed from our earliest days. Heidegger describes this readiness as "the background of ... primary familiarity, which itself is not conscious or intended but is rather present in [an] unprominent way" (Heidegger, 1985: 189). Thus, assuming that we are in the world of modern computing, when we enter our places of work we see desks, chairs, computers, printers, network points and so forth. We do not perceive a jumble of surfaces, wires and inexplicable grey boxes. Having made a case for familiarity how do we re-cast this into an account which might reveal how this works in practice?

The question then, is what is the psychological basis of familiarity? From what we have seen it does not appear to involve a cognitive representation and the manipulation of that knowledge in a way congruent with a mental model. Instead it appears to resemble the way in which an expert chess master player perceives patterns of pieces which the novice cannot (e.g. Chase and Simon, 1973); or way in which an academic is about to locate themselves in the information space offered by a journal paper more accurately than the less experienced reader (e.g. Dillon and Scaap, 1996) or the tennis pro being able to predict the direction of an opponent's serve better than a novice (e.g. Farrow and Abernethy, 2003). So perhaps familiarity may be better understood as changes in perception rather than the creation of knowledge per se. Our own work lends weight to this hypothesis (e.g. Van De Walle et al., 2003; Turner et al., 2004). In a longitudinal study of seniors learning to use a PC we found evidence for changes in their perceptions of interactive technology accompanying their growing familiarity with it. We witnessed changes in their perception of information technologies from, for example, something quite alien to a means of warding off or at least delaying many of the effects of aging (loss of mobility, contact with the outside world, communications with friends and relatives).

\footnotetext{
${ }^{2}$ It should be noted that Heidegger was also an unrepentant member of the Nazi party a fact which should not be neglected when consulting his work.
} 
So, for the purposes of this discussion this perspective on intuitiveness will be subsumed under the single term "intuitiveness as familiarity".

\subsection{Intuitiveness and Embodiment}

However there is more to intuitiveness than just know-how or familiarity. There are many researchers who describe their interactive systems as intuitive but emphasize their graspability, physicality and tangibility. Such system often employ a tangible user interface (TUI). Ishii and Ullmer (1997) introduced us to their vision of "Tangible Bits" which has subsequently formed a focus of subsequent research into tangible and ambient computing. An important feature of this is the "grasp and manipulate" approach which couples everyday physical objects and surfaces and corresponding digital representations. Since this initial work, tangible systems have appeared two broad forms, namely, those which employ some form of interactive workbench and those which are more "free-standing". Of the former group, Bricks (Fitzmaurice et al., 1995), Urp (Underkoffler and Ishii, 1999) and Illuminating Clay (Piper et al., 2002) are prominent examples. TUIs couple physical representations with digital representations creating interactive systems that are computationally mediated but generally not identifiable as 'computers' per se.

TUIs make use of physical representations - such as modelling clay (as in Piper et al. above) and physical drawing boards to manipulate their digital equivalents. TUIs integrate representation and control which GUIs necessarily keep distinct. GUIs have a Model - View - Control structure which involves the use peripheral devices to control a digital representation of what we are working with the results of which are displayed on an output device. TUIs, in contrast, employ a MCRpd model in which the view component is split between Rep- $p$ (physical representation) and Rep- $d$ (digital representation). This model highlights the tight linkage between the control and physical representation.

A second larger group of tangible systems and devices are very diverse and include examples of games and toys (e.g. Cheok et al., 2002; Bonanni, et al. 2006), storytelling applications (Zhou et al., 2004) artistic applications and installations (e.g. Baxter et al. 2001; Sengers et al., 2002) among many more. There are also numerous example of systems described as intuitive which make reference to both familiarity and tangibility. For example, Mackay et al. (1998) describe an augmented reality (AR) prototype designed to support air traffic controllers and their interactions with paper flight strips. Flight strips are physical cards which contain aircraft flight information and are used by flight controllers to track their movement in a manner which is directly analogous to the movement of the aircraft themselves. By adopting an AR approach, Mackay and her colleagues sought to avoid the problem of "forcing an abrupt change in the controllers' familiar styles of interaction."

Kasabach et al. (1998) have reported the development of digital ink. Digital Ink is described as a writing tool that "both understands people's handwriting, and allows them to turn any writing surface into a personalized interaction surface". Its creators note that its use is intuitive it that it is based on something familiar - a pen, which of course is also a tangible artefact. In all, this points to intuitiveness reflecting our embodied.

Whitehead writing in his Science and the Modern World observed that "We have to admit that the body is the organism whose states regulate our cognition of the world. The unity of the perceptual field therefore must be a unity of bodily experience" (Whitehead, 1925: 91). This theme was then significantly developed by Merleau-Ponty who argued that it is only though our lived bodies do we have access to what he describes as the "primary world". The world and the lived body together form an intentional arc which binds the body to the world. This arc anchors us in and to the world. The intentional arc is the knowledge of how to act in a way that "coheres" with one's environment bringing body and world together. "The life of consciousness - cognitive life, the life of desire or perceptual life - is subtended by an "intentional arc" which projects round about us our past, our future, our human setting, our physical, ideological and moral situation" (ibid: 136). For MerleauPonty the intentional arc embodies the interconnection of skilful action and perception. Commenting on this Dreyfus (1996) argues that we need to distinguish three different interpretations of embodiment. The first perspective is to recognise the physical dimensions of the human body and its innate capacities (in many ways this resembles ergonomics). Secondly, everyday practice allows us to refine our skills for coping with things and situations. Finally, Gibson's $(1977,1986)$ treatment of 
affordance reflects our embodiment and perceptions of the human world, e.g. what affords walking on, carrying and so forth correspond to our body's capacities and skills. To this in his later work he adds such things as mail boxes afford mailing letters. This kind of affordance has been called a complex or cultural affordance (e.g. Turner, 2005) or a significance (Ilyenkov, 1977). Thus our bodies determine how we perceive and interact with the world - innate structures, basic general skills, and cultural skills. Merleau-Ponty includes these three dimensions of embodiment as the means by which the body makes the world available.

By describing this aspect of intuitive as embodied allows us to distinguish this form of intuitiveness from familiarity and physical ergonomics (see also Winograd, 2000; Sharlin et al. 2004). In short, these various forms of tangible systems which exploit our embodiment will be treated as examples of "intuitiveness as embodiment".

\section{Intuitiveness as Action-Perception Coupling}

We have considered evidence for two distinct aspects of intuitiveness and that they may be linked as evidenced by the recurring themes of perception and affordance. Interestingly, Kant described intuition (from which intuitiveness springs) as one of the basic cognitive faculties roughly equivalent to perception. Davidson discusses intuitiveness as follows:

"The primary signification [of intuition] follows the etymology. Intuition literally means seeing though the eye, visual perception: and, if we draw a distinction between intueor in classical usage and its near synonyms [ ... ] we should say that in intueor is implied intentness of observation, rather than bare seeing [...] If, then, we ask at this stage what Intuition is, we obtain as answer - the apprehension or discerning of a thing actually present to the eye; and it is distinguished, on the one hand, from the revival of that thing in memory ..."

Davidson (1882:304 - italics in the original)

More recently research has presented evidence that it is more meaningful to couple action and perception than to treat tem separately. Work in cognitive science (e.g. Clark, 1997), robotics (e.g. Schaal, 1999), the study of skilled behaviour (e.g. Montagne et al., 2000) and developmental psychology (e.g. Thelen and Smith, 1994; Bertenthal et al., 1997) have suggested that there is close coupling between perception and action. For example, Bertenthal et al. (ibid) have noted that action and perception are being increasingly treated as being closely coupled in the regulation of coordinated movements. This coupling, they continue, is necessary to ensure stable and environmentally appropriate action patterns are produced in response to demands of the situation. So, for example, in moving from one location to another, we could not expect to be able to control our motor systems action effectively if they did not respond to incoming perceptual information. And Thelen and Smith have suggested that the interplay between thought and action may be so ubiquitous and so fundamental that all of our early knowledge is built "though the time-locked interactions of perceiving and acting in particular contexts" (1994: 217).

But it was, of course, Gibson $(1977,1986)$ who was the first to highlight action-perception coupling with his work on visual perception and affordance. For Gibson, perception is not mediated by internal representations instead it is geared to detecting and exploiting the affordance which the environment provides as he put it, "We must perceive in order to move, but we must also move in order to perceive" (1979: 223). For example, Lederman and Klatzky (1987) have demonstrated that people detect the affordance of objects, such as size, texture, weight, hardness, and temperature, from haptic explorations. There is also substantial evidence from studies of the neural basis of perception and action. For example, Grèzes and Decety (2002) using positron emission tomography have shown that those parts of the brain responsible for motor representation are activated in response to the perception of the affordances of objects. They conclude that "perception of objects automatically affords actions that can be made towards them" (p.212). (Interestingly in reviewing the literature on the neural basis of affordance they note an earlier study by Jeanerod et al. (1994) who found the actions elicited by affordance were affected by the familiarity one had with objects.)

However this treatment of action-perception coupling is, perhaps, a little too narrow to account for all aspects of intuitiveness particularly when we consider Merleau-Ponty's treatment of the intentional arc. Wartofsky (1979) treats perception as an historical process rather than one which is a function of 
the interpretation of sensory data. He argues that it is culturally acquired and is a process which continues to expand with additional individual or group experience. He begins, with a treatment of affordance (in a manner which is not dissimilar to Gibson's account) with the recognition that perception is a functional aspect of the interactions between animals and their environments. He also observes that there is a reciprocal relationship between the animal and its environment: while the perceived world of the animal can be treated as a map or an image of the animals activities, the senses of animals themselves are shaped by the purposive interactions which the species has with the environment, or as he puts it, "Rather, the very forms of perceptual activity are now shaped to, and also help to shape an environment created by conscious human activity itself. This environment is the world made by praxis - nature transformed into artefact, and now embodying human intentions and needs in an objective way." An example of this may be found in Goodwin and Goodwin's (1998) study of operational staff at an airport. The study demonstrates how perceptions of artefacts (flight information displays, documentation linking flights, destinations and aircraft, the position of the aircraft themselves on the stand...) and their perceived properties or characteristics are shaped by the histories of both the personnel involved and the artefacts themselves. The Goodwins further observe that such perceptions are always grounded in the familiarity individuals have with given situations, tasks and mediating artefacts. Returning to why Nintendo's Wii-Mote Control is intuitive - it is because it reflects the tight coupling between action and perception but this is in the context of "baseball", "tennis" and "swordplay" the sources of which are products of our cultures. But more than this we see the action of our familiarity with games as providing an epistemic core to these activities. Swinging the Wii-Mote Control to make "contact" with an on-screen ball (or whatever) reflects the action-perception make up of the activity but its attractiveness, its meaningfulness as such is a product of our understanding, our deep familiarity with games whether real or virtual. Thus it would seem that we need to extend the account of action-perception coupling to include the social, cultural and historic.

\section{Discussion}

Most accounts of HCI research begin by stating a problem, describing its resolution and indicating how the work contributes to better design or evaluation practice. This paper is perhaps the reverse of this as it has begun with a given, namely that intuitiveness is desirable, is important, it underpins good design and so on and then argued that it may be underpinned by an (extended) account of actionperception coupling. Given this, can we return to some of those examples of systems which claim intuitiveness and determine why they are so attractive? All of them, of course, involve behaviours such as reaching, grasping, modelling or swinging which exploits the coupling between perception and action. But these activities are more than a little light exercise as they are meaningful to those involved. Those tangible systems such as Illuminating Clay are designed to support cooperative design work. We might speculate that perhaps much of the appeal of the intuitiveness of interaction effectively frees the designers to focus on those tasks which make use of higher cognitive functions. Indeed the idea of "off-loading" aspects of our interaction with technology has been explored by Robertson et al. (1993) with their Cone Tree system which sought to switch the burden of navigating a file store having to use our memories to making use of visual reasoning.

Perhaps, more generally, intuitive systems work because they make use of pre-existing or "precompiled" action-perception (motor) routines and socially (and culturally / historically) acquired "know-how" which free us - or at least reduces the burden - of having to engage with the interacting rather than using to system to achieve our ends - whether it is work or fun.

\section{Further work}

Reber (1989) writing of intuitiveness notes that there is "probably no cognitive process that suffers from such a gap between phenomenological reality and scientific understanding. Introspectively, intuition is one of the most compelling and obvious cognitive processes; empirically and theoretically, it is one of the processes least understood by contemporary cognitive scientists". To this discussion we have now added the dimensions of embodiment and familiarity as to this body of psychological research.

We may also have contributed to understanding counter-intuitiveness. Having argued for a what is essentially a non-representational account of intuitiveness, counter-intuitiveness cannot be attributed 
to the use of poorly constructed or executed mental models. So, faced with a counter-intuitive system we can speculate that (a) we automatically and unconsciously seek to make use of our familiarity with similar systems and (b) identify the affordances the system offers. Both activities prime effective prime subsequent behaviour both in terms of our "know-how" and the activation appropriate actionperception (motor) routines. Being counter-intuitive we can reasonably expect a breakdown in the system's use and thus we are faced with the cognitive burden of putting aside this priming and readiness to cope and tackling the system in a more considered manner. As we do not approach the use of systems afresh each time, it is perhaps overcoming these expectations (being primed and ready) which gives rise to the experience of counter-intuitiveness.

Finally, as we now have a plausible account of the dimensions of intuitiveness and how it might work could this be extended to other attributes of human-computer interaction. If, for example, we were to recast of intuitiveness as an affordance or perhaps a cluster of affordances (corresponding to familiarity and embodiment) might not a similar approach to the deconstruction of other affordances?

\section{References}

Baxter, B., Scheib, V., Lin, M. C. and Manocha, D. (2001) DAB: Interactive Haptic Painting with 3D Virtual Brushes. Proceedings of SIGGRAPH 200, 12-17 August 2001, Los Angeles.

Bertenthal, B.I., Rose, J. L. and Bai, D. L. (1997) Perception-Action Coupling in the Development of Visual Control of Posture. Journal of Experimental Psychology: Human Perception and Performance, 23(6), 1631-1643

Bonanni, L., Lieberman, J., Vaucelle, C. and Zuckerman, O. (2006) PlayPals: Tangible Interfaces for Remote Communication and Play. Proceedings Of The Conference On Human Factors In Computing Systems (CHI '06), 574-579.

Bowman, D.A., Kruijff, E., LaViola, J.J. and Poupyrev, I. (2001) An Introduction to 3D User Interface Design. Presence: Teleoperators and Virtual Environments. 10(1), 96-108.

Brewley, W. L., Roberts, T. L., Schroit, D. and Verplank, W. (1983) Human factors Testing in the Design of Xerox's 8010 'Star' Office Workstation, Proceedings of the Chi'83, 72-77.

Chase, W.G. and Simon, H.A. (1973) Perception in chess. Cognitive Psychology, 4, 55-81.

Clark, A. (1997) Being There: Putting Brain Body and World Together Again. Cambridge, MA: MIT Press.

Darken, R.P. and Silbert, J.L. (1993) A toolset for navigation in virtual environments. Proceedings $O f$ The $6^{\text {th }}$ ACM Symposium On User Interface Software And Technology, Atlanta, Georgia, 157-165.

Dillon, A. and Scaap, D. (1996) Expertise and the Perception of Shape in Information. Journal of the American Society for Information Science, 47 (10), 786-780.

Dourish, P. (2001) Where the Action Is. Cambridge, MA: MIT Press.

Dreyfus, H. L. (1991) Being-in-the-world: A Commentary on Heidegger's Being and Time, Division 1. Cambridge, MA: MIT Press.

Dreyfus, H.L. (1988) Mind Over Machine: The Power of Human Intuition and Expertise in the Era of the Computer. NY: Free Press.

Dreyfus, H.L. (1996) The Current Relevance of Merleau-Ponty's Phenomenology of Embodiment. Electronic Journal of Analytic Philosophy, 4 (Spring), no pages numbers.

Farrow, D. and Abernethy, B (2003) Do expertise and the degree of perception - action coupling affect natural anticipatory performance? Perception, 32(9), 1127 - 1139

Fauconnier, G. and Turner, M. (2003) The Way We Think: Conceptual Blending and the Mind's Hidden Complexities. Basic Books, NY.

Fitzmaurice, G.W., Ishii, H. and Buxton, W.A.S. (1995) Bricks: Laying The Foundations For Graspable User Interfaces. Proceedings Of The Conference On Human Factors In Computing Systems (CHI '97), 442-449.

Frensch, P.A. (1998) One Concept, Multiple Meanings: On How To Define The Concept Of Implicit Learning. In M.A. Stadler and P.A. Frensch (Eds) Handbook of Implicit Learning. Sage Publications,, 47-104,

Gibson, J. J. (1977) The Theory Of Affordances. In R. Shaw and J. Bransford, Eds., Perceiving, Acting and Knowing. New York: Wiley, 67 - 82. 
Gibson, J.J. (1986) The Ecological Approach To Visual Perception, Lawrence Erlbaum Associates, Hillsdale, NJ.

Goodwin, C. and Goodwin, M.H. (1998) Seeing as a situated activity: Formulating Planes, In Y. Engestrom and D. Middleton (Eds.) Cognition and Communication at Work, CA: Cambridge University Press.

Grèzes, J. and Decety, J. (2002) Does Visual Perception Of Object Afford Action? Evidence From A Neuroimaging Study. Neuropsychologia, 40, 212-222.

Halasz, F. and Moran, T.P. (1982) Analogy Considered Harmful. Proc. CHI'82, 383-386.

Hartson, D. and Hix, H.R. (1993) Developing User Interfaces. John Wiley and Sons.

Heidegger, M. (1927/1962) Being and Time. (Translated by J. Macquarrie and E. Robinson) New York: Harper Collins

Heidegger, M. (1985). History of the Concept of Time. Bloomington: Indiana University Press.

Hix, D. and Hartson, H. R. (1993) Developing User Interfaces: Ensuring Usability Through Product \& Process. New York: John Wiley.

Ilyenkov, E. (1977) The Problem of the Ideal (Translated by A. Bluden). Progress Publishers. Also available from http://www.marxists.org/archive/ilyenkov/works/ideal/ideal.htm

Ishii H. and Ullmer B. (1997) Tangible Bits: Towards Seamless Interfaces Between People, Bits and Atoms. Proceedings Of The Conference On Human Factors In Computing Systems (CHI '97), 234241.

Johnson, J., Roberts, T. L., Verplank, W., Irby, C. H., Beard, M. and Mackey, K. (1989) The Xerox Star: A Retrospective, IEEE Computer, 11-26 and 28-29.

Kara, K. S., Perry, T. J. and Krolczyk, M. J. (1997) Testing For Power Usability. Proceedings of the Conference on Human Factors in Computing Systems (CHI '97), Atlanta, Georgia, 235 - 235.

Lakoff, G. and Johnson, M. (1999) Philosophy in the Flesh. NY: Basic Books.

Lederman S.J. and Klatzky R.L. (1987) Hand movements: a window into haptic object recognition. Cognitive Psychology. 19, 342-68.

Marcus, A. (1993) Human Communications Issues in Advanced UIs. Communications of the ACM, 36(4), 100-109.

Merleau-Ponty, M. (1945/1962) Phenomenology of Perception. (Translated by Colin Smith) London: Routledge Classics.

Montagne, G., Buekers, M., Camachon, C., de Rugy A. and Laurent, M. (2003) The learning of goaldirected locomotion: A perception-action perspective. The Quarterly Journal of Experimental Psychology: Section A, 56(3), 551 - 567.

Norman, D. A. (1988). The Psychology Of Everyday Things. NY: Basic Books.

Norman, D. A. (1999) Affordance, Conventions and Design. interactions, may + june, 38-42.

Piper, B., Ratti, C. and Ishii, H. (2002) Illuminating Clay: a 3-D tangible interface for landscape analysis. Proceedings Of The Conference On Human Factors In Computing Systems (CHI '02), ACM Press, New York, 355-362.

Raskin, J. (1994) Intuitive Equals Familiar. Communications of the ACM. 37(9), 17.

Raskin, J. (2000) The Humane Interface. Addison Wesley.

Reber, A. S. (1989) Implicit Learning and Tacit Knowledge. Journal of Experimental Psychology: General, 118( 3), 219-235

Robertson, G.C., Card, S.K. and MacKinlay, J.D. (1993) Information visualization using 3D interactive animation. Communications of the ACM, 36(4), 56-71.

Schaal, S. (1999) Is imitation learning the route to humanoid robots? Trends in Cognitive Science, 3(6), 233-242.

Sharlin, E., Watson, B., Kitamura, Y., Kishino, F and Itoh, Y. (2004) On tangible user interfaces, humans and spatiality. Personal and Ubiquitous Computing, 8, 338-346

Shneiderman, B. (1992) Designing The User Interface: Strategies For Effective Human-Computer Interaction (2nd edition) New York: Addison-Wesley.

Siio, I. and Tsujita, H. (2006) Mobile Interaction Using Paperweight Metaphor. Proceedings of the Conference On Human Factors In Computing Systems (CHI '06), 1325-1330.

Smith, D. C., Irby, R. Kimball, B. Verplank, W. and E. Harlsem (1982) Designing the Star User Interface. Byte, 7(4), 242-282. 
Thelen E. and Smith, L. (1994) A Dynamics Systems Approach to the Development of Cognition and Action. Cambridge, MA: MIT Press.

Thelen, E. (1995) Time-scale dynamics in the development of an embodied cognition. In R. Port and T. van Gelder (Eds.) Mind In Motion. Cambridge, MA: MIT Press.

Thomson, D.G. (1878) Intuition and Inference. Mind, 3(11), 339-349.

Turner, P. (2005) Affordance As Context. Interacting With Computers. 17(6), 787-800.

Turner, P., Davenport, E. and Van De Walle, G. (2004) Familiarity as Changing Perception. Proc. European Conference on Cognitive Ergonomics 12, York, September 2004.

Van De Walle, G., Turner, P. and Davenport, E. (2003) The Phenomenology of Familiarity. Proc. Interact 2003, 273-286.

Wartofsky, M. (1979) Models: Representation and Scientific Understanding, Reidel Publishing Company, Dordrecht, Holland.

Westcott, M. R. (1968) Toward A Contemporary Psychology Of Intuition. New York: Holt, Rinehart and Winston.

Whitehead, A.N. (1925/ 1997) Science and the Modern World. New York: Free Press.

Winograd, T. (2000) Interaction Spaces for the Twenty-First Century. In J. M. Carroll (Ed.) HumanComputer Interaction in the New Millennium. Addison-Wesley, 259-278.

Zhou, Z., Cheok, A.D. and Pan, J. (2004) 3D Story Cube: An Interactive Tangible User Interface For Storytelling With 3D Graphics And Audio. Personal and Ubiquitous Computing, 8, 374-376. 